\title{
PERAN STAKEHOLDERS DALAM PENGELOLAAN OBJEK WISATA ALAM SIWANG PARADISE DI DESA SIWANG KOTA AMBON
}

\section{THE ROLE OF STAKEHOLDERS IN THE MANAGEMENT OF THE SIWANG PARADISE NATURAL TOURISM OBJECT IN SIWANG VILLAGE, AMBON CITY}

\author{
Oleh \\ Fanny Soselissa $^{1 *)}$ dan Billy Seipalla ${ }^{2)}$ \\ ${ }^{1,2}$ Dosen Jurusan Kehutanan Fakultas Pertanian Universitas Pattimura \\ Jl.Ir.M.Putuhena, Kampus Poka Ambon \\ Email:fanny.kace@gmail.com
}

\begin{tabular}{l|l} 
Diterima : 3 Februari 2021 & Disetujui: 20 Maret 2021
\end{tabular}

\begin{abstract}
Abstrak
Potensi objek daya tarik wisata alam siwang paradise akan memiliki nilai daya tarik yang tinggi jika ditunjang oleh peran stakeholders dalam pengelolaan dan pengembangan. Tujuan dari penelitian ini adalah menganalisis peran stakeholders dalam pengelolaan dan pengembangan objek daya tarik wisata alam siwang paradise,dan apa saja kendala yang dialami stakeholders dalam melakukan pengelolaan dan pengembangan secara optimal terhadap objek tersebut. Metode yang digunakan adalah deskriptif kualitatif, penentuan responden berdasarkan teknik snowball sampling, analisis dilakukan secara induktif berdasarkan fakta dan hasil wawancara dengan responden dan actor kunci. Hasil penelitian menunjukkan bahwa stakeholder yang terlibat dalam pengelolaan objek siwang paradise adalah actor kunci (pemilik kawasan) dan aktor utama (masyarakat sekitar). Kendala dalam pengelolaan di objek siwang adalah karena belum adanya trust dalam diri pemilik kawasan untuk melibatkan stakeholders pendukung yang dalam hal ini adalah swasta, LSM, dan akademisi. Sehingga pengelolaan objek dalam mengembangkan berbagai kesiapan produk daya tarik wisata menjadi lambat dan berjalan tidak optimal. Dampak yang terlihat dari adanya pengelolaan adalah dampak ekonomi, melalui peningkatan pendapatan keluarga, dampak social, terjadinya pengurangan pengangguran, terbukanya akses jalan, semakin lancar moda transportasi ojek sehingga memudahkan masyarakat untuk beraktifitas. Sedangkan dampak ekologis adalah pengelolaan dilakukan dengan memperhatikan kebersihan lingkungan dari sampah, dan berbasis pada daya dukung kawasan objek.
\end{abstract}

Kata kunci : stakeholders, pengelolaan siwang paradise,

Abstract

The potential of the natural tourist attraction of Siwang Paradise will have a high attractiveness value if it is supported by the role of stakeholders in management and development. The purpose of this study is to analyze the role of stakeholders in the management and development of the natural tourist attraction of Siwang Paradise, and what obstacles are experienced by stakeholders in optimally managing and developing these objects. The method used is descriptive qualitative, the determination of respondents is based on snowball sampling technique, the analysis is carried out inductively based on facts and the results of interviews with respondents and key actors. The results showed that the stakeholders involved in the management of the Siwang Paradise object were the key actors (area owners) and the main actors (surrounding communities). Constraints in the management of the Siwang object are due to the lack of trust within the area owner to involve supporting stakeholders, in this case the private sector, NGOs, and academics. So that the management of objects in developing various readiness of tourist attraction products becomes slow and runs not optimally. The visible impact of the management is the economic impact, through increasing family income, social impact, reducing unemployment, opening up road access, making motorcycle taxis easier to use, making it easier for people to do their activities. While the ecological impact is the management is carried out by paying attention to the cleanliness of the environment from waste, and based on the carrying capacity of the object area.

Keywords: stakeholders, management of siwang paradise, 


\section{PENDAHULUAN}

Indonesia merupakan negara seribu pulau besar dan kecil yang memiliki seribu potensi daya tarik baik dalam bentuk keanekaragaman flora fauna, landscape alam, serta keragaman budaya lokal dan adat istiadat. Keanekaragaman hayati dan keanekaragaman etnik budaya yang berlimpah tentu berpotensi untuk dijadikan objek daya tarik wisata yang potensial untuk menciptakan minat kunjungan wisnus dan wisman (Latupapua, 2015; Wahyono dan Rahmawati, 2017). Potensi supply dan demand yang ada merupakan salah satu asset penting bagi negera untuk dijadikan sebagai destinasi wisata alam (nature tourism), wisata budaya (culture tourism), maupun wisata petualangan yang menantang (adventure tourism) (Widodo et al 2018).

Karakteristik Pulau Ambon sebagai pulaupulau kecil yang terdiri dari 90 persen laut, tentunya memiliki ragam potensi daya tarik wisata pantai dengan pasir putih halus seperti di Pantai Natsepa, pantai berbatu karang pencakar langit di Pantai Larike, Batu Suanggi di Wakasihu, pesona karang yang berbentuk seperti pintu di Pintu Kota, dan air laut yang biru dan jernih seperti di Pantai Liang. Namun selain itu ada juga destinasi wisata alam bernama Siwang Paradise yang letaknya di perbukitan Gunung Nona, Kecamatan Nusaniwe, Kota Ambon, yang juga tak kalah menawan. Berada di ketinggian $500 \mathrm{~m}$ dpl membuat Siwang Paradise menjadi objek potensial yang menyajikan pesona keindahan alam dipadu dengan udara yang segar, pepohonan yang rindang, serta kicauan suara burung yang menambah pesona daya tarik alam pegunungan (Tribunnews, 2020).

$$
\text { Potensi yang ada dalam upaya }
$$

pengembangan objek daya tarik wisata membutuhkan berbagai peran dari seluruh stakeholders, baik pemerintah, swata maupun masyarakat Pengembangan supply dan demand wisata menjadi indicator penting dari pembangunan pariwisata nasional yang berkelanjutan (sustainable tourism development), untuk itu perlu adanya keterpaduan secara optimal dan terintegrasi dalam kesatuan sector dalam mendukung pembangunan pariwisata berkelanjutan dan mampu memberdayakan masyarakat (Andi,2004). Selain itu, pembangunan pariwisata berkelanjutan diharapkan mampu meningkatkan pertumbuhan ekonomi dalam bentuk PAD, serta adanya perubahan kesejahteraan melalui peningkatan taraf hidup masyarakat dan peningkatan usaha kecil menengah. .Pendapat serupa juga dikemukakan dalam hasil penelitian (Rahim, 2012; Amsyari, 2018) bahwa pembangunan destinasi wisata di berbagai daerah di Indonesia membutuhkan berbagai kontribusi dari semua pihak (actor pembangunan) secara aktif dalam mempersiapkan supply dan demand yang memiliki nilai jual tinggi, dan memiliki tingkat keunikan tinggi. Sedangkan dalam penelitian Berliandaldo et al.,(2021) dikemukakan bahwa sinergitas dalam berbagai peran actor pembangunan mampu menciptakan pembangunan destinasi wisata yang memiliki nilai daya saing tinggi, karena didukung 
dengan ketersedian sarana prasarana wisata yang optimal.

\section{Berlakunya Undang-Undang No. 23} Tahun 2014 Tentang Pemerintahan Daerah, menjadikan. Pemerintah Kota Ambon memiliki kewenangan dalam melakukan pengembangan destinasi wisata melali kesiapan supply dan demand yang optimal di daerahnya.

Siwang Paradise merupakan objek daya tarik wisata alam pegunungan yang menawarkan pesona view alam pegunungan, pantai dan kota yang memanjang sekitar $1 \mathrm{~km}$ yang terletak di Desa Siwang Kecamatan Nusaniwe Kota Ambon.

Objek Siwang Paradise memiliki nilai daya tarik tersendiri jika dibandingkan dengan objek pegunungan yang ada di sekitarnya. Kealamian kawasan objek yang masih asri, ditumbuhi dengan berbagai jenis pohon dan pesona view alam sekitar dengan pemandangan lepas ke laut dan kota, menambah kesan indah atas pesona alam Kota Ambon sebagai berkat Tuhan Yang Maha kuasa.

Pesona alam dan keindahan objek Siwang Paradise ternyata masih belum mampu memberikan nilai daya tarik yang potensial dalam menarik demand wisnus, dan wisman, hal ini terlihat dari hasil wawancara dengan salah satu pengelola objek, didapatkan informasi bahwa, telah terjadi penurunan jumlah kunjungan yang sangat signifikan. Hasil wawancara menjelaskan bahwa sejak dibuka Januari 2020 jumlah kunjungan sekitar 1000-3000 pengunjung per hari, dan saat penelitian (Maret 2021) jumlah kunjungan hanya sekitar 100-150 orang (jumlah ini hanya saat weekend), sedangkan hari kerja (senin-jumat) hanya sekitar 20-50 orang.

Permasalahan yang terjadi saat ini menjadi indikator untuk melakukan penelitian lebih mendalam, apakah factor terjadinya penurunan jumlah kunjungan dipengaruhi karena belum adanya keterlibatan stakeholders dalam pengelolaan, ataukah ada faktor lainnya. Karena Kondisi tinggi rendahnya minat pengunjung sangat ditentukan oleh ketersediaan jumlah objek daya tarik yang dapat dinikmati saat berwisata, di samping kelengkapan amenitas dan aksesibilitas di daerah tujuan wisata tersebut (Damanik dan Weber 2006). Pendapat serupa juga dikemukakan dalam (Fuqoha, 2021) bahwa bentuk pengelolaan suatu destinasi wisata yang tidak dilakukan secara optimal dan tanpa keterlibatan dan peran aktif stakeholders, akan mempengaruhi dan berkorelasi terhadap minat kunjungan pengunjung ke objek tersebut. Berdasarkan uraian masalah yang dikemukakan di atas maka kajian secara komprehensif terhadap keterlibatan stakeholders dalam pengelolaan objek Siwang Paradise perlu dilakukan.

Adapun tujuan penellitian yang ingin dicapai adalah mengidentifikasi stakeholders yang terlibat dalam pengelolaan; menganalisis peran stakeholders; dan dampak yang terjadi atas pelaksanaan kolaborasi dan sinergitas antar stakeholders. 


\section{METODE PENELITIAN}

Penelitian ini merupakan penelitian deskriptif kualitatif. Lokasi penelitian di Desa Siwang Kecamatan Nusaniwe Kota Ambon. Pemilihan lokasi secara purposive sampling Penentuan informan didasarkan pada teknik purposive sampling yaitu teknik pemilihan informan untuk mendapatkan sumber data berdasarkan orang yang dianggap paling tahu tentang apa yang diharapkan oleh peneliti. Selain itu, didukung dengan menggunakan teknik snowball sampling yaitu apabila informan belum memberikan data yang lengkap, maka akan menggunakan informan-informan lain sehingga informan semakin banyak dan informasi akan semakin lengkap (Sugiyono, 2011)

Jenis data penelitian ini meliputi data primer dan data sekunder.Data primer yaitu data yang diperoleh secara langsung dari sumbernya melalui observasi lapangan, wawancara dengan para informan dan dokumentasi. Data stakeholder diperoleh dengan menggunakan kuesioner tertutup untuk memastikan kepentingan dan pengaruh para pihak terhadap pengolaan dan pengembangan objek siwang paradise. Stakeholders yang di

\section{HASIL DAN PEMBAHASAN}

\section{Identifikasi Stakeholers}

Identifikasi stakeholder dalam penelitian ini mengacu pada Maryono (2005), di mana dalam hasil analisis terhadap stakeholders yang selama ini terlibat dalam pengelolaan objek wisata siwang paradise dibedakan menurut tiga kelompok yaitu; stakeholder primer, stakeholder kunci, dan maksud adalah semua pihak yang memiliki wewenang dalam pengelolaan dan dipandang potensial untuk bisa mengembangkan objek daya tarik alam dan budaya yang memiliki nilai jual tinggi sebagai destinasi wisata. (Nurkhalis, et al., 2018).

Data sekunder yaitu data yang mendukung data primer berupa yang merupakan hasil penelitian sebelumnya, referensi dari buku, internet, dokumen atau arsip. Teknik analisis data menggunakan model Miles and Huberman (Sugiono, 2011) terdiri dari mereduksi data, menyajikan data dan menyimpulkan data. Metode analisis data yang dilakukan bersifat induktif berdasarkan fakta-fakta yang ditemukan di lapangan dan kemudian disusun menjadi sebuah konsep pengembangan (Sugiono, 2011). Dalam penelitian ini dibatasi pada empat focus penelitian yaitu: 1) melakukan identifikasi para stakeholders yang terlibat dalam pengembangan wisata di siwang paradise, 2) menganalis bentuk keterlibatan dari para stakeholders, dan 3) melihat dampak yang terjadi dari adanya kolaborasi dan sinergitas antar stakeholders.

stakeholder pendukung. Stakeholder Primer (utama).merupakan stakeholder yang terkena dampak secara langsung baik dampak positif maupun negatif dari suatu rencana atau proyek serta mempunyai kaitan kepentingan langsung dengan kegiatan tersebut (Maryono et al, 2005). Berdasarkan definisi di atas masyarakat 
sekitar merupakan stakeholder primer, karena kegiatan wisata yang dikembangkan nantinya akan berdampak bagi masyarakat sekitar daerah tujuan wisata. Sedangkan Stakeholder kunci adalah mereka yang memiliki kewenangan legal dalam hal pengambilan keputusan (Maryono et al., 2005). Dalam penelitian ini stakeholders kunci diidentifikasikan berdasarkan kewenangannya dalam mengambil keputusan terkait dengan proses penetapan pengelolaan dan pengembangan objek wisata Siwang Paradise. yaitu pemilik kawasan objek (keluarga Wattimena). Sedangkan stakeholders pendukung adalah stakeholder yang tidak memiliki kepentingan langsung terhadap proyek tetapi memiliki kepedulian yang besar terhadap proses pengembangan (Maryono et al., 2005). Stakeholders ini dapat menjadi intermediaries atau fasilitator dalam proses pengembangan dan cukup berpengaruh terhadap pengambilan keputusan. Dalam penelitian ini yang dapat dikategorikan stakeholder pendukung yaitu pemerintah, LSM, akademisi/peneliti, serta pihak swasta.

Berdasarkan hasil observasi dan wawancara diperoleh informasi bahwa objek wisata alam siwang paradise merupakan destinasi wisata yang secara legal, merupakan kawasan milik keluarga (milik pribadi) yang dikelola bersama-sama dengan keluarga dan masyarakat sekitar, sehingga stakeholder kunci dalam penelitian ini adalah pemilik objek siwang paradise yaitu keluarga Wattimena (bapak Wem Wattimena). Pengelolaan kawasan objek siwang paradise sejak awal dibuka banyak dilakukan bersama masyarakat sekitar objek, tanpa adanya keterlibatan stakehlders pendukung.

;Pemilik objek menyiapkan berbagai fasilitas dalam menunjang daya tarik wisata siwang paradise secara swadaya,baik dana maupun tenaga. Bentuk aktifitas yang dilakukan adalah menyiapkan tempat bersantai, panggung foto, spot selfie, food and beverage. Semua fasilitas yang ada menjadi tanggungjawab pemilik kawasan dengan dibantu oleh masyarakat sekitar tanpa melibatkan adanya kontribusi pemerintah, LSM atau swasta. Kondisi ini tentunya memberikan dampak secara langsung terhadap pengelolaan dan pengembangan objek itu sendiri.

Dalam penelitian Wakka, (2014) dikemukakan bahwa kontribusi stakeholders utama atau primer sangat berkaitan dengan pengelolaan secara teknis terkait penetapan aturan atau kebijakan dalam pengelolaan, pengembangan objek daya tarik wisata dan pengembangan yang berbasis pada masyarakat.

Stakeholder kunci merupakan actor kunci dalam pengelolaan dan pengembangan suatu destinasi wisata alam siwang paradise. Sedangkan stakeholder pendukung adalah pihak yang tidak berkaitan langsung terhadap keputusan dalam pengelolaan dan pengembangan siwang paradise, namun memiliki keprihatinan dan kepedulian sehingga ikut menyuarakan pendapat yang bisa mempengaruhi sikap stakeholder kunci. Dalam pengelolaan dan pengembangan objek wisata siwang paradise stakeholders pendukung yang terlibat hanya kelompok pemuda dan organisasi lokal yang memberikan saran dan masukan dalam 
pengelolaan dan pengembangan, sedangkan pemerintah, peneliti/akademisi,LSM dan swasta

\section{Mengidentifikasi Peran Stakeholders}

Berdasarkan identifikasi stakeholders yang selama ini terlibat dalam pengelolaan dan pengembangan objek daya tarik Siwang Paradise, selanjutnya dilakukan identifikasi implementasi belum secara optimal terlibat dalam pengelolaan di siwang paradise.

pelaksanaan peran stakeholders di lokasi amatan, dengan menggunakan metode realisasi peran stakeholders dalam pengembangan wisata di siwang paradise analisis peran dalam bentuk implementasi pelaksanaan kegiatan ekowisata disajikan pada Tabel.1.

Tabel.1. Hasil Identifikasi dan Peran Stakeholders Dalam Pengelolaan Objek Siwang Paradise

\begin{tabular}{|c|c|c|}
\hline $\begin{array}{l}\text { Stakehol der } \\
\text { Kunci }\end{array}$ & Kontribusi bagi pengelolaan wisata objek siwang paradise & Analisis penilaian \\
\hline $\begin{array}{c}\text { Pemilik } \\
\text { Objek } \\
\text { Siwang } \\
\text { Paradise }\end{array}$ & $\begin{array}{l}\text { 1. Pemantapan status hukum kawasan sebagai Destinasi } \\
\text { Objek Wisata Alam } \\
\text { 2. Pemanfataan secara optimal SDA berdasarkan } \\
\text { prinsip kelestarian; } \\
\text { 3. Mengembangkan pengelolaan, dan pemanfaatan } \\
\text { SDA; } \\
\text { 4. Peningkatan fasilitas dan sarana pendukung objek; } \\
\text { 5. Memberikan ruang bagi masyarakat untuk turut } \\
\text { terlibat dalam bentuk partisipasi masyarakat dalam } \\
\text { pengelolaan kawasan; } \\
\text { 6. Melakukan pelestarian lingkungan objek; } \\
\text { 7. Melakukan promosi; dan } \\
\text { 8. Pengawasan dan pencegahan kerusakan sarana } \\
\text { prasarana objek }\end{array}$ & $\begin{array}{l}\text { Peran actor kunci sudah } \\
\text { dilakukan dan butuh } \\
\text { kerjasama dengan actor } \\
\text { pendukung lainnya. }\end{array}$ \\
\hline $\begin{array}{l}\text { Stakeholders } \\
\text { Pendukung }\end{array}$ & Kontribusi & Analisis Penilaian \\
\hline $\begin{array}{l}\text { Akademisi } \\
\text { /peneliti }\end{array}$ & $\begin{array}{l}\text { 1. Melakukan kajian-kajian ilmiah terkait pengelolaan dan } \\
\text { konservasi kawasan objek } \\
\text { 2. Menentukan kelayakan suatu kegiatan/proyek dari sisi } \\
\text { keilmuan yang relevan. } \\
\text { 3. Menemukan solusi-solusi pengelolaan yang inovatif } \\
\text { pada kelestarian keanekaragaman hayati dan budaya } \\
\text { lokal masyarakat. } \\
\text { 4. Melakukan riset dalam menunjang konservasi kawasan } \\
\text { melalui kapasitas kawasan (daya dukung kawasan). }\end{array}$ & Belum dilakukan \\
\hline Swasta & $\begin{array}{l}\text { 1. Penyedia fasilitas amenitas, dan aksesibilitas } \\
\text { 2. Sumber donasi. }\end{array}$ & Belum terlibat \\
\hline LSM & $\begin{array}{l}\text { 1.Sebagai pendamping bagi masyarakat: } \\
\text { 2. membangun pemahaman masyarakat tentang supply dan } \\
\text { demand; } \\
\text { 3.membangun kelembagaan lokal yang kreatif dalam } \\
\text { pengelolaan objek wisata; } \\
\text { 4. menyiapkan tourism attraction;mengantarkan masyarakat } \\
\text { pada network wisata. } \\
\text { 5. promosi gagasan ekowisata berbasis masyarakat, } \\
\text { dan pemasaran produk ekowisata. }\end{array}$ & Belum terlibat \\
\hline
\end{tabular}




\begin{tabular}{|c|l|c|}
\hline $\begin{array}{c}\text { Stakeholder } \\
\text { Utama }\end{array}$ & \multicolumn{1}{|c|}{ Kontribusi } & \multicolumn{1}{|c|}{ Analisis Penilaian } \\
\hline Masyarakat & $\begin{array}{l}\text { 1. Terlibat dalam penyedian fasilitas dan sarana wisata } \\
\text { 2. Turut terlibat dalam kegiatan menunjang keamanan } \\
\text { kawasan. } \\
\text { 3. Terlibat menyiapkan makan dan minuman bersama pihak } \\
\text { pemilik kawasan. } \\
\text { 4. menunjang moda transportasi angkutan (ojek). } \\
\text { 5. Menunjang dalam menyiapkan area parker. }\end{array}$ & $\begin{array}{c}\text { Kontribusi sudah dilakukan, } \\
\text { namun belum optimal }\end{array}$ \\
\hline
\end{tabular}

Sumber Data Primer 2021.

Berdasarkan pada hasil analisis peran stakeholders pada Tabel.1, dapat dijelaskan bahwa keterlibatan masing-masing stakeholders belum berjalan sesuai dengan fungsinya. Masih adanya gab yang besar antara stakeholder kunci dengan kedua stakeholder lainnya, sehingga implementasi dari peran masing-masing tidak terealisasi secara sinergis dan maksimal dalam pengelolaan dan pengembangan wisata siwang paradise. Hal ini terindikasi selama proses wawancara dan observasi dengan pemilik objek bahwa pengelolaan siwang paradise sejak dibuka pada tahun 2020 memang belum ada keterlibatan dengan stakeholders lainnya. (pemerintah, LSM, akademisi/peneliti dan swasta).

Pengelolaan dilakukan oleh pemilik objek dengan beberapa teman dan masyarakat dalam menyiapkan fasilitas wisata, seperti spot tempat duduk, tempat selvie, warung makanan dan minuman (sarimi dan beberapa jenis minum kaleng dan aqua), serta tempat bersantai.

Kondisi Jalan menuju kawasan objek siwang paradise masih berbatu dan belum beraspal. Beberapa pengunjung yang tidak memiliki kendaraan harus berjalan kaki menaiki area yang berbukit dengan tipe jalan yang belum aspal, becek, dan belum ditata dengan area parkir yang baik. Selain itu sarana pendukung seperti kamar mandi,dan WC juga masih dalam bentuk yang sederhana (bukan dalam bentuk permanen). Kebutuhan air bersih juga masih disupply oleh mobil air, karena di area tersebut belum difasilitasi dengan adanya PAMD. Dari kondisi fasilitas dan sarana pendukung yang ada, menunjukkan bahwa objek siwang paradise dengan kondisi alam yang indah, dan menarik sebagai potensi objek yang mampu menarik minat kunjungan pengunjung, perlu juga dilengkapi dengan kesiapan fasilitas dan sarana pendukung yang memadai.

Kendala utama belum adanya keterlibatan dengan pihak pemerintah dan LSM atau swasta sangat dipengaruhi juga oleh kepercayaan (trust) dari pemilik objek. Pemilik kawasan siwang paradise sering diliputi perasaan bimbang dan ragu jika harus melibatkan stakeholder pendukung dalam pengelolaan dan pengembangan. Hal ini ternyata dipicu oleh pemikiran bahwa ketika bentuk kerjasama yang dilakukan dengan pihakpihak pemerintah maupun swasta, akan berdampak pada hilangnya hak kepemilikan kawasan (ada pembagian hak atas kawasan).

Dari hasil wawancara tersebut dapat dijelaskan bahwa pemahaman pemilik kawasan tentang networking belum terbentuk. Sehingga 
dalam pengelolaan dan pengembangan hanya dilakukan dalam kapasitas diri sendiri tanpa mau melibatkan pihak lainnya. Sedangkan dalam pengelolaan dan pengembangan suatu destinasi wisata baik objek alam, budaya maupun man made tidak mungkin dapat berjalan maksimal jika tidak melibatkan peran dan partisipasi aktif stakeholders lainnya (Mahfud et al.,2015)..

Pendapat yang sama dikemukakan dalam Berliandaldo (2021), tentang peran stakeholders dalam pengelolaan kebun raya Cibinong yang menyatakan keberhasilan dalam pengembangan wisata perlu adanya peran stakeholders yang saling bekerjasama, bersinergi, dan berkolaborasi untuk mencapai keberlanjutan pengembangan. CIFOR (2004), menyatakan bahwa pengelolaan dan pengembangan wisata berbasis masyarakat menggunakan pendekatan multipihak agar dapat menyelaraskan persepsi tentang tujuan pengelolaan dan pengembangan wisata serta mendukung tercegahnya dampak dari pembangunan sektor pariwisata yang tidak diinginkan dan menjadi landasan untuk mengatasi masalah

Pendekatan kolaborasi antar stakeholder mulai muncul sebagai respons atas tuntutan kebutuhan akan manajemen pengelolaan sumber daya yang baru untuk meraih hasil yang maksimal dan sesuai yang diharapkan. Dalam hal ini, semua pihak yang terlibat memposisikan dirinya sama atau sesuai dengan perannya masing-masing, sehingga saling menghormati dan menghargai dan tidak akan mucul konflik dikemudian hari. Pengelolaan dan pengembangan wisata membutuhkan dukungan dari berbagai pihak. Partisipasi pemangku kepentingan atau stakeholder erat kaitannya dengan kapasitas yang dimiliki stakeholder sebagai salah satu modal dalam pengelolaan ekowisata. Kapasitas ini khususnya adalah kapasitas pengembangan jejaring stakeholder yang mutlak dibutuhkan dalam pengelolaan wisata yang bersifat multisektoral (Pamungkas, 2013).

Pendapat lainnya yang mendukung hasil penelitian dinyatakan dalam hasil penelitian Hijriati dan Mardiana (2017), bahwa partisipasi stakeholders perlu dilibatkan secara aktif dalam menunjang optimalisasi pengelolaan wisata. Wahyono dan Rahmawati (2017) menyatakan bahwa preferensi stakeholder menjadi esensial ketika pengelolaan dan pengembangan objek wisata perlu dikembangkan. Karena keikutsertaan stakeholders akan membawa pengelolaan dengan tanggungjawab dan peran sesuai dengan kompetensi dari masing-masing stakeholders. Pelaksanaan penggelolaan wisata tentunya tidak dapat terlaksana apabila para stakeholder yang terlibat ini tidak memiliki kemampuan untuk melaksanakan dan mengembangkannya. Dengan banyaknya kepentingan yang dimiliki oleh stakeholder yang terlibat, maka diperlukan kerjasama yang kuat yang dilandasi dengan rasa saling percaya antara para stakeholder tersebut (Pamungkas, 2013). Peran aktif stakeholders merupakan modal utama yang sangat penting dalam pengelolaan destinasi wisata alam. Karena dalam pengelolaan objek wisata tidak lagi bersifat terpusat hanya pada satu actor, namun dibutuhkan 
keterlibatan aktif secara kolaboratif bersama masyarakat sekitar objek sebagai bagian dari

\section{Dampak dari Kolaborasi Stakeholder}

Dampak yang muncul dari adanya kolaborasi dan sinergitas antar stakeholder dalam pengelolaan dan pengembangan siwang paradise dapat terlihat pada tiga aspek yaitu

\section{a. Dampak Ekonomi}

Dampak ekonomi yang akan timbul dari adanya keterlibatan stakeholders dalam pengelolaan dan pengembangan, salah satunya menambah pemasukan ekonomi keluarga. Adanya pengelolaan dan pengembangan akan memberikan peluang hadirnya kunjungan pengunjung untuk datang dan menikmati segala aktifitas wisata yang disediakan oleh objek tersebut. Kehadiran pengunjung akan memberikan dampak ekonomi melalui keterlibatan masyarakat dalam menyiapkan fasilitas makanan dan minuman, moda tarnsportasi, bensin, parkiran, dan tiket masuk dalam objek.

Dampak ekonomi ini secara langsung akan dirasakan oleh stakeholder, karena pada saat menikmati objek tersebut, pengunjung akan membayar semua hospitality yang dinikmati kepada pengelola dan masyarakat. Penerimaan manfaat ekonomi secara langsung tentunya akan memberikan minat peduli terhadap konservasi lingkungan objek, karena asset daya tarik lingkungan mampu menciptakan tambahan pendapatan bagi pengelola objek dan masyarakat sekitar kawasan. Khomzi et al, (2000) mengemukakan bahwa adanya pengembangan pengelolaan (bukan hanya pemerintah namun seluruh aspek masyarakat) Oktami (2018).

objek daya tarik memberikan peluang kerja sampingan bagi masyarakat sekitar objek, serta mengurangi pengangguran. Pendapat yang sama juga dikemukakan dalam Rizal et al., (2017) bahwa pengelolaan dan pengembangan objek wisata dengan melibatkan berbagai stakeholders akan memunculkan banyak usaha kecil menengah (UKM), Selain itu juga, secara tidak langsung akan bermunculan para pedagang baik itu yang nantinya akan dikelola langsung oleh pihak mitra maupun yang tumbuh secara tidak sengaja di sekitar kawasan objek Siwang Paradise.

Pertumbuhan usaha ini tentunya berkorelasi dengan adanya pengunjung ke kawasan. Untuk itu kesiapan dalam mengelola objek agar dapat tampil menarik dan memiliki banyak objek untuk dinikmati harus dikemas lebih optimal oleh pengelola dan stakeholders. Karena melalui kontribusi stakeholders dalam pengelolaan dan pengembangan akan meningkatkan kesejahteraan masyarakat sekitar, sehingga kedepannya perlu adanya penataan terkait para pedagang, UKM, yang akan mencari nafkah dari pengembangan.

Pemerintah Kota Ambon dalam hal ini selaku regulator, dapat menyusun suatu strategi pengembangan UKM dan pemberdayaan masyarakat sehingga dapat meningkatkan perekonomian daerah secara tidak langsung.. para aktor yang terlibat tentunya memiliki peran 
masing-masing dalam berbagai bentuk pengelolaan, mulai dari tahapan perencanaan hingga pengembangan dan promosi, sehingga harus dapat dipahami bahhwa bentuk pengelolaan secara kolaboratif akan mampu mengoptimalkan pengelolaan dan pengembangan objek daya tarik wisata (Mahfud et al 2015; Redyanto et al., 2018).

b.Dampak Sosial

Dampak sosial yang timbul dari adanya pengelolaan siwang paradise bersama stakeholders adalah

1) Menumbuhkan kesadaran bagi masyarakat sekitar untuk menata lingkungan sosialnya agar dapat terjaga dengan baik (tidak terjadi kenakalan, mabuk mabukan, tidak ada aksi pemerasan kepada pengunjung, dan pencurian milik pegunjung). Hal ini dapat terjadi karena pemuda diberdayakan dalam pengelolaan objek wisata siwang.

2)Terbukanya akses bagi masyarakat,

3)Terbukanya peluang kerja sehingga mengurangi pengangguran,

4) Tersedianya infrastuktur sarana pendukung yang secara langsung juga dapat dinikmati oleh masyarakat sekitar.

Berdasarkan hasil wawancara dengan pengelola, dapat dijelaskan bahwa dampak ekonomi dan social ini sudah terjadi sejak objek siwang paradise dibuka, yaitu dengan adanya kunjungan maka terjadi peningkatan pendapatan yang langsung dirasakan, pendapatan dari pengelolaan objek ini malah melebihi pendapatan rutin dari pihak pengelola sebagai staf pemancar. Selain itu, melalui keterlibatan dalam penyiapan sarana dan fasilitas para pemuda ikut terlibat sehingga mengurangi tingkat pengangguran. Pengembangan dan pengelolaan siwang paradise akan memberikan efek positif bagi masyarakat dilingkungan terdekat, hal ini dikarenakan akan menyerap tenaga kerja sebagai penopang SDM Pembangunan infrastruktur pendukung pun akan dinikmati oleh masyarakat sekitar dalam memanfaatkan jalan yang telah dikembangkan sebagai penunjang akses ke objek

\section{c. Dampak Ekologis}

Dampak lingkungan yang timbul dari adanya pengelolaan objek siwang paradise adalah terkait kepedulian lingkungan dalam menjaga kebersihan. Jumlah kunjungan yang meningkat akan menciptakan kondisi lingkungan yang banyak sampah. Namun msayarakat sekitar objek berusaha untuk bisa menanggulangi kondisi sekitar dari adanya sampah yang berserakan, dengan menyiapkan tempat sampah, dan mengelola sampah melalui proses dibakar. Pendapat yang sama juga dikemukakan dalam hasil penelitian Hijriati \& Mardiana, (2015), bahwa masyarakat selaku pengelola objek mulai menyadari pentingnya kebersihan lingkungan, sehingga masyarakat melakukan pengelolaan terhadap sampah yang ada di dalam dan sekitar objek.

Selain peduli sampah, pengelola kawasan juga melakukan pengelolaan dengan memperhatikan daya dukung kawasan objek. Baik kemampuan daya dukung fisik, social, maupun ekologis. Pengelolaan dan pengembangan yang berorientasi pada pengelolaan berbasis daya dukung tentunya akan menciptakan pengelolaan 
yang memperhatikan kemampuan alam dalam mendukung sarana prasarana wisata, aksesibilitas yang sesuai dengan kemampuan dan karakteristik alam itu sendiri.

Pengelolaan di objek siwang paradise, dalam mempersiapkan berbagai fasilitas dan sarana bagi wisatawan/pengunjung, tidak melakukan perubahan alam, dengan menebang pohon atau merubah kondisi ekologis lahan, hanya memanfaatkan lahan kosong untuk dijadikan area fasilitas tempat bersantai, spot foto, dan tempat makan. Namun pengelolaan limbah sampah plastic belum terlihat selama proses penelitian.sehingga pengelola kawasan objek siwang paradise perlu mengikut sertakan para stakeholders dalam menunjang pengelolaan lingkungan yang bersifat green produk.

\section{KESIMPULAN}

Hasil identifikasi stakeholder menunjukkan bahwa stakeholders yang terlibat dalam pengelolaan hanya stakeholder kunci (pemilik objek) dan stakeholders utama (masyarakat sekitar). Sedangkan stakeholdedrs pendukung seperti pemerintah, akademisi, swasta dan LSM belum memberikan kontribusi terhadap pengelolaan dan pengembangan di objek wisata alam Siwang Paradise. Hasil analisis dengan belum optimalnya peran stakeholders dalam pengelolaan mengakibatkan belum adanya pembagian peran dan tanggungjawab dalam mengoptimalkan pengelolaan siwang paradise. Sehingga optimalisasi objek daya tarik dalam bentuk atraksi, amenitas dan aksesibilitas dari suatu destinasi tidak tersedia secara optimal dan pengembangan berjalan sangat lambat.

\section{DAFTAR PUSTAKA}

Amsyari, F. (2018). Kolaborasi antar Stakeholder dalam Pengembangan Pariwisata Religi Sunan Ampel di Kota Surabaya. Jurnal Kebijakan Dan Manajemen Publik, 6(1), pp.10-21.

Berliandaldo M, Chodiq, a., Fryantoni d.,2021. Kolaborasi dan Sinergitas Antar Stakeholder dalam Pembangunan Berkelanjutan Sektor Pariwisata Di Kebun Raya Cibinong. INOBIS: Jurnal Inovasi Bisnis dan Manajemen Indonesia 4 (2).pp.221-234.

CIFOR. 2004. Pembangunan Pariwisata Berbasis Masyarakat. CIFOR. Bogor.

Damanik J, dan Weber H, 2006. Perencanaan Ekowisata Dari Teori ke Aplikasi. Diterbitkan atas kerjasama dengan Pusat Studi Pariwisata (PUSPAR) UGM dengan Penerbit Andi.Yogjakarta.

Fuqoha, 2021. Analisis Kebijakan Pemerintah Daerah Kota Cilegon Dalam Penetapan Desa Wisata Watu Lawang. Jurnal Administrasi Negara (AsIAN) Vol 9 (1).

Hijriati, E., \& Mardiana, R. (2015). Pengaruh Ekowisata Berbasis Masyarakat Terhadap Perubahan Kondisi Ekologi, Sosial Dan Ekonomi Di Kampung Batusuhunan, Sukabumi. Sodality: Jurnal Sosiologi Pedesaan, 2(3), 146-159. https://doi.org/10.22500/sodality.v2i3.94 22.

Khomzi, I. R., Handono, S. Y., \& Trianawati, A. (2020). Sinergisitas Stakeholder Dalam Pengembangan Desa Wisata Pujon Kidul Kabupaten Malang. Agribusiness Journal, 13(2), 25-35. https://doi.org/10.15408/aj.v13i2.13948. 
Latupapua, Y. Th.,2015. Implementasi Peran Stakeholder dalam Pengembangan Ekowisata di Taman Nasional Manusela (TNM) di Kabupaten Maluku Tengah. Jurnal Agroforestri X Nomor 1 ISSN 1907-7556.

Nurkhalis, H.Arief, T.Sunarminto. 2018. Analisis Stakeholders dalam Pengembangan Ekowisata di Hutan Adat Ammatoa Kajang Sulawesi Selatan. Jurnal Pariwisata, Vol. 5 No. 2 September 2018.

Mahfud, M. (2015). Peran Dan Koordinasi Stakeholder Dalam Pengembangan Kawasan Minapolitan Di Kecamatan Nglegok, Kabupaten Blitar. Jurnal Administrasi Publik Mahasiswa Universitas Brawijaya, 3(12), 20702076.

Oktami A.E, Tutut S, dan Harios. A., 2018. Partisipasi Masyarakat Dalam Pengembangan Ekowisata Taman Hutan Raya Ir H Djuanda. Jurnal Media Konservasi Vol. 23 No. 3 Desember 2018: 236-243.

Rizal, A., Sumartik, \& Zulfikar. (2017). Analisa Dampak Ekonomi, Sosial, Lingkungan Terhadap Pengembangan Objek Wisata Banyu Biru Di Desa Sumberejo, Winong, Pasuruan Jatim. Forum Manajemen Indonesia (FMI) KE-9 , November 2017, ISBN : 978- 602-855731-3, 1-14.

Sugiyono. 2011. Metode Penelitian Pendidikan Pendekatan Kuantitatif, kualitatif, dan R\&D.Bandung: Alfabeta.

Pamungkas, G. (2013). Ekowisata Belum Milik Bersama: Kapasitas Jejaring Stakeholder dalam Pengelolaan Ekowisata (Studi Kasus: Taman Nasional Gunung Gede Pangrango). Journal of Regional and City Planning, 24(1), 49. https://doi.org/10.5614/jpwk.2013.24.1.4.

Redyanto, F. W., Salahudin, S., \& Salviana, V. (2018). Model Kerjasama Antar
Stakeholders Dalam Pengembangan Wisata Budaya Dusun Sejo Kabupaten Pasuruan. LOGOS Journal of Local Government Issues, 1-24.

Wakka, Kadir. 2014. Analisis Stakeholders Pengelolaan Kawasan Hutan dengan Tujuan Khusus (KHDTK) Mengkendek, Kabupaten Tana Toraja, Provinsi Sulawesi Selatan. Jurnal Penelitian Kehutanan Wallacea Vol.3 No.1, April 2014 : 47-55.

Wahyono. W.H, Rahmawati D., 2017. Preferensi Stakeholder dalam Pengembangan Ekowisata Mangrove Gunung Anyar Surabaya. Jurnal Teknik ITS Vol. 6, No. 2 (2017), 2337-3520 (2301-928X Print).

https://www.tribunnews.com/regional/2020/09/20 /menikmati-siwang-paradise 